\title{
Differential Expression of Synaptophysin and Synaptoporin mRNAs in the Postnatal Rat Central Nervous System
}

\author{
Béatrice Marquèze-Pouey, ${ }^{a}$ William Wisden, Maria Luisa Malosio, ${ }^{\mathrm{b}}$ and Heinrich Betz \\ Zentrum für Molekulare Biologie Heidelberg, Universität Heidelberg, D-6900 Heidelberg, Germany
}

\begin{abstract}
Synaptophysin and synaptoporin are two homologous integral membrane proteins of small synaptic vesicles. Here, the distribution of the corresponding transcripts in the CNS of the rat was investigated by in situ hybridization using sequence-specific oligonucleotide probes. Synaptophysin mRNA was abundantly distributed through all major brain regions, whereas synaptoporin transcripts displayed a more restricted localization in telencephalic structures. Resolution at the cellular level disclosed a differential labeling of distinct cell types in different areas, suggesting that synaptophysin and synaptoporin are expressed by specific subpopulations of central neurons. Consistent with this conclusion, relative synaptoporin mRNA contents were found to vary between different brain regions during postnatal development, whereas synaptophysin transcripts showed a more uniform increase during the same period.
\end{abstract}

Synaptic vesicles represent the most abundant subcellular structures in the mammalian nervous system and are considered to be csscntial components of the neurotransmitter release apparatus at chemical synapses (Kelly, 1988). Recent experiments indicate that the major population of these secretory organelles in brain, the electron-translucent small synaptic vesicles, contain transmembrane channels that may be implicated in homeostasis and/or exocytosis of vesicular contents (Rahaminoff et al., 1988, 1989). Synaptophysin, a major integral membrane protein of small synaptic vesicles (Buckley and Kelly, 1985; Jahn et al., 1985; Wiedenmann and Franke, 1985), shares its transmembrane topology (Buckley et al., 1987; Leube et al., 1987; Südhof et al., 1987; Johnston et al., 1989) with connexins, the subunits of gap junction proteins (Kumar and Gilula, 1986; Paul, 1986). These membrane proteins span the lipid bilayer four times, with both $\mathrm{N}$ - and C-termini located cytoplasmically. Upon reconstitution into planar bilayers, purified synaptophysin displays channel activity resembling that of native and iso-

\footnotetext{
Reccived Feb. 18, 1991; revised Apr. 26, 1991; accepted May 23, 1991.

We are indebted to P. Knaus for providing synaptophysin clone S41, G. Munke for help in preparation of sections, $H$. Monyer for the gift of some brain sections, and P. H. Seeburg for providing facilities. We thank M. Gratzl and our colleagues for critical reading of the manuscript. This work was supported by Bundesministerium für Forschung und Technologie (BCT 365/1), Deutsche Forschungsgemeinschaft (Leibniz Programm and SFB 317), and Fonds der Chemischen Industrie

B.M.-P. and W.W. hold long-term EMBO fellowships. This article is dedicated to Prof. T. Sakeki on the occasion of his 50 th birthday.

Correspondence should be addressed to Heinrich Betz, Max-Planck-Institut für Hirnforschung, Deutschordenstrasse 46, D-6000 Frankfurt 71, Germany.

a Present address: Faculté de Medicine-Nord, University of Marseille, F-13010 Marseille, France.

b Present address: Department of Pharmacology, University of Milano, I-20129 Milano, Italy.

Copyright (C) 1991 Society for Neuroscience $0270-6474 / 91 / 113388-10 \$ 05.00 / 0$
}

lated gap junction protein preparations (Thomas et al., 1988). Cross-linking experiments indicate that native synaptophysin has an oligomeric structure; di- (Johnston and Südhof, 1990), tetra- (Rehm et al., 1986), and hexameric (Thomas et al., 1988) models have been proposed.

Recently, we have used homology screening of a rat brain cDNA library to identify cDNAs encoding a novel synaptophysin variant, synaptoporin (Knaus et al., 1990). Throughout the predicted transmembrane regions, synaptophysin and synaptoporin display a high degree of sequence identity. Their extended cytoplasmic tails characterizcd by degenerate pentapeptide repeats are, however, highly dissimilar. Using sequencespecific antibodies, synaptoporin has been shown to cofractionate with synaptophysin in small synaptic vesicles (Knaus et al., 1990). The function of these two homologous proteins in the vesicle membrane is presently unknown. By analogy with connexins (Loewenstein, 1987), a possible role in the formation of transient two bilayer-spanning channels connecting the vesicular lumen with the extracellular space during exocytosis, the so-called "synaptopores" (Pfenninger et al., 1972) or "fusion pores" (Almers and Tse, 1990), has been suggested (Thomas et al., 1988; Betz, 1990; Knaus et al., 1990). The recent identifcation of a putative synaptophysin receptor, physophilin, in synaptic plasma membrane fractions is consistent with this hypothesis (Thomas and Betz, 1990).

In view of the large diversity of neurotransmitters found in mammalian brain, transmitter- or pathway-specific functions may be assigned to each of these putative vesicular channel proteins. Immunocytochemical (Wiedenmann and Franke, 1985) and immunoprecipitation (Floor and Feist, 1989) data indicate the presence of synaptophysin in most $(\geq 90 \%)$ synaptic vesicles of rat brain. Also, synaptophysin transcripts are ubiquitously found in RNA isolated from different brain regions and peripheral neuroendocrine organs (Leube et al., 1987). Synaptoporin mRNA in contrast appears to be less abundant (Knaus et al., 1990). Here, we present a comparative in situ hybridization analysis of synaptophysin and synaptoporin transcripts in the rat CNS. Our data reveal a differential expression of these vesicular membrane proteins in distinct areas of the developing and adult brain.

\section{Materials and Methods}

Oligonucleotide probes. Oligonucleotide probes [45 base pairs $(\mathrm{bp})$ ] of unique sequence were synthesized and purified using a $\mathrm{NaP}_{5}$ column (Pharmacia). The probe sequences derived from the rat synaptophysin cDNA (Leube et al., 1987) were as follows: ASy1, complementary to nucleotides 514-557 (GAG AAC ATT ATC AAG GAG ATG CCC ATG TGC CGC CAG ACA GGG AA) and ASy2, complementary to nucleotides 232-278 (TAC TTT GAT GCA CCC TCC TGC GTCAAA GGG GGC ACT ACC AAG ATC TT). A sense oligonucleotide (SSy) 
exactly complementary to the ASy1 antisense probe was used as a control. Probe sequences for rat synaptoporin transcripts (Knaus et al., 1990) were ASo1, complementary to nucleotides 1135-1180 (AGC AGC TAC AAT CAA GGC GGC TAC AAC CAA GAC AGT TAT GGG TCA A), and ASo2, complementary to nucleotides 922-965 (AAA GAA GTC CTG TTG CTG ATG TCA GCT TGC AAG CAG CCT TCC AA). A sense probe SSo exactly complementary to the ASol antisense probe was used as a control.

Probes were $3^{\prime}$ end-labeled to identical specific activities (in the range of $\left.1 \times 10^{7} \mathrm{dpm} / \mu \mathrm{g} 4 \times 10^{7} \mathrm{dpm} / \mu \mathrm{g}\right)$ with $5^{\prime}-\left[\alpha^{-35} \mathrm{~S}\right]-\mathrm{dATP}(1200 \mathrm{Ci} /$ mmol; New England Nuclear) using terminal deoxynucleotidyl transferase (GIBCO, Bethesda Research Laboratories), with a 30:1 molar ratio of dATP:oligonucleotide.

In situ hybridization. Adult rat brain samples were dissected within $2 \mathrm{hr}$ of death and stored (wrapped in foil to prevent freeze-drying) at $-70^{\circ} \mathrm{C}$ until use. Cryostat sections $(12 \mu \mathrm{m})$ were mounted onto poly-Llysine-coated slides, and samples were allowed to dry for $30 \mathrm{~min}$ at room temperature before being fixed $(5 \mathrm{~min})$ in $4 \%(\mathrm{w} / \mathrm{v})$ paraformaldehyde in phosphate-buffered saline (PBS). After two washes in PBS and dehydration in $70 \%(\mathrm{v} / \mathrm{v})$ ethanol, the slides were stored in $95 \%$ $(\mathrm{v} / \mathrm{v})$ ethanol at $4^{\circ} \mathrm{C}$ until use (Wisden et al., 1991). Hybridization was performed at $42^{\circ} \mathrm{C}$ in $50 \%(\mathrm{v} / \mathrm{v})$ formamide, $4 \times$ saline-sodium citrate (SSC), and $10 \%(\mathrm{w} / \mathrm{v})$ dextran sulfate under a parafilm cover. Sections were washed to a final stringency of $1 \times \mathrm{SSC}$ at $55^{\circ} \mathrm{C}$ and exposed to Kodak X-Omat film at room temperature, or dipped in Kodak NTB2 emulsion. Clear hybridization signals were visible after 1 (synaptophy$\sin$ ) to 4 (synaptoporin) d; however, to increase signal-to-noise ratios, longer exposure times were routinely chosen (4-15 d for films, 2-8 weeks for emulsions). After development, emulsion-coated slides were counterstained with $0.1 \%(\mathrm{w} / \mathrm{v})$ thionin. To examine the specificity of the signals observed, parallel sections were hybridized with two independent antisense oligonucleotides constructed to different regions of each transcript. Furthermore, control experiments were done with the sense 45bp oligonucleotide probes SSy and SSo as detailed above. Some sections were also hybridized with the antisense probes in presence of a large excess (50-fold) of the unlabeled oligonucleotide.

Northern blots. Extraction of RNA from adult rat brain was performed according to Cathala et al. (1983). PolyA ${ }^{+}$RNA was isolated by oligo-dT chromatography (Aviv and Leder, 1972), separated on a $1 \%$ formaldehyde-agarose gel, transferred to a nylon filter (Hybond-N, Amersham), and fixed by UV irradiation. Blots were hybridized with synaptophysin (ASy1) and synaptoporin (ASo1) antisense oligonucleotides that were $3^{\prime}$ end-labeled with $5^{\prime}-\left[\alpha{ }^{-32} \mathrm{P}\right]-\mathrm{dATP}(6000 \mathrm{Ci} / \mathrm{mmol}$ New England Nuclear). Hybridization and washing were performed under the same conditions as the in situ hybridization (see above), except that dextran sulfate was omitted from the hybridization solutions. Blots were exposed to Kodak X-Omat film at $-70^{\circ} \mathrm{C}$, using intensifying screens.

PCR amplification. First-strand cDNA synthesized from polyA ${ }^{+}$RNA served as template for PCR. Amplification of synaptophysin transcripts was performed by using a sense primer corresponding to nucleotides 10-36 (Leube et al., 1987) and the antisense oligonucleotide ASyl (see above). PCR amplification of synaptoporin transcripts was performed using a sense probe corresponding to nucleotides 492-504 (Knaus et al., 1990) and the antisense oligonucleotide ASol. Amplification conditions were as described in Knaus et al. (1990). Amplification products were separated on a $1 \%$ agarose gel, transferred to Hybond-N, and hybridized with the ${ }^{32} \mathrm{P}$-labeled synaptophysin clone $\mathrm{S} 41$ (nucleotides $1-968$ ) or a ${ }^{32} \mathrm{P}$-labeled Xho fragment of the synaptoporin clone $\mathrm{SH} 14$ (nucleotides $426-1987)$ in $50 \%(\mathrm{w} / \mathrm{v})$ formamide, $5 \times$ SET $(1 \times$ SET contained $0.15 \mathrm{M} \mathrm{NaCl}, 0.03 \mathrm{~m}$ Tris- $\mathrm{HCl}, \mathrm{pH} 8.0$, and $1 \mathrm{~mm}$ EDTA). After washing in $2 \times \mathrm{SET}, 1 \times \mathrm{SET}$, and $0.2 \times \mathrm{SET}$ at $65^{\circ} \mathrm{C}$, the filters were autoradiographed at $-70^{\circ} \mathrm{C}$ for $2 \mathrm{hr}$.

\section{Results}

\section{Specificity of oligonucleotide probes}

Synaptophysin and synaptoporin cDNA sequences display low homology in the segments encoding the two postulated intravesicular loops (between transmembrane regions M1-M2 and M3-M4) and the cytoplasmic tail region (Knaus et al., 1990). This was exploited for synthesizing oligonucleotide probes specific for each mRNA. We used two different antisense oligonucleotides for detecting synaptophysin transcripts, ASy1, which corresponds to part of the second, and ASy2, deduced from the

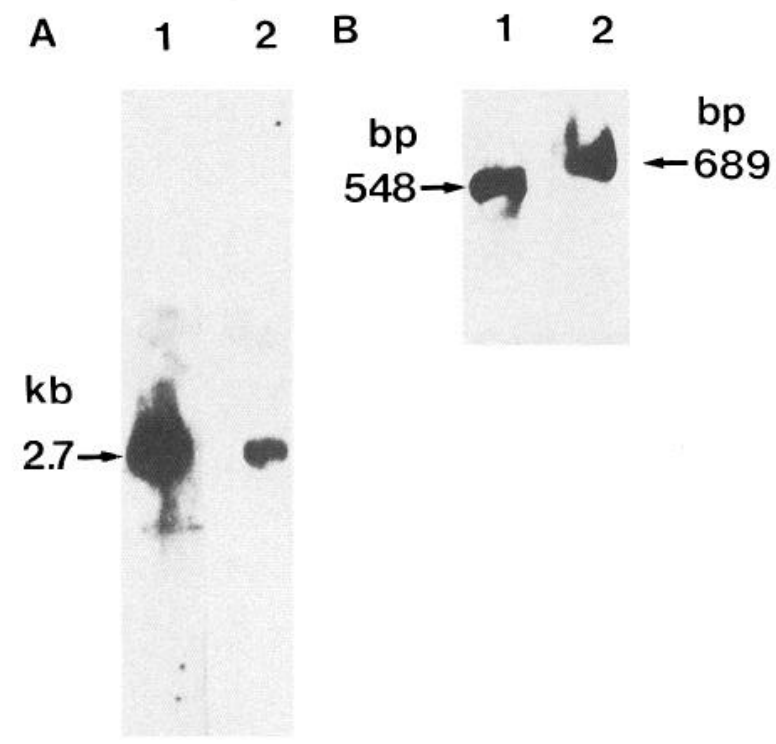

Figure 1. Northern blot and PCR analysis showing specificity of oligonucleotide hybridization. $A$, Northern analysis of polyA ${ }^{+}$RNA isolated from rat brain. Thirty micrograms of RNA were separated on an agarose-formaldehyde gel, blotted, and hybridized to oligonucleotides ASy1 (lane 1) or ASol (lane 2). Blots were exposed for 2 d. B, Amplification of synaptophysin (lane 1) and synaptoporin (lane 2) transcripts by PCR was performed on cDNA synthesized with polyA ${ }^{+}$RNA from total brain. Amplification products were obtained using as antisense primers ASy1 (lane 1) for synaptophysin transcripts and ASol (lane 2) for synaptoporin transcripts. After electrophoresis and blotting, specific sequences were visualized by hybridization to synaptophysin probes (lane 1) or synaptoporin (lane 2) probes. The sizes of the expected fragments corresponded to their calculated lengths of 548 bp (lane I) and 689 bp (lane 2), respectively.

coding sequence of the first, intravesicular loop regions. Two equivalent antisense probes, ASol and ASo2, covered portions of the second intravesicular loop and the cytoplasmic tail coding region of the synaptoporin mRNA. The specificity of these oligonucleotides was tested by Northern blot analysis and PCR (Fig. 1). Northern analysis (Fig. 1A), when performed with ASy 1 (lane 1) and ASo 1 (lane 2) antisense oligonucleotides, revealed the presence of two RNA bands of similar size (approximately 2.7 kilobases). This corresponds to the previously determined sizes of both synaptophysin (Leube et al., 1987) and synaptoporin (Knaus et al., 1990) transcripts. To confirm that indeed two different mRNAs were revealed by these probes, PCR amplification (Fig. $1 B$ ) was in addition performed using the antisense oligonucleotides ASy1 (lane 1) for synaptophysin transcripts and ASol (lane 2) for synaptoporin transcripts in combination with specific sense oligonucleotides deduced from the synaptophysin and synaptoporin cDNAs. Exclusively fragments of the expected sizes were obtained in both cases (not shown). Furthermore, when the amplification products were hybridized with ${ }^{32} \mathrm{P}$-labeled synaptophysin or synaptoporin cDNA probes, fragments obtained with oligonucleotide ASy1 hybridized only to the synaptophysin (Fig. $1 B$, lane 1) sequences, and those obtained with oligonucleotide ASol hybridized only to the synaptoporin (Fig. 1B, lane 2) sequences; no cross-hybridizations were seen when using the opposite cDNAs (data not shown). We therefore conclude that our antisense oligonucleotides specifically revealed the complementary RNA sequences. 

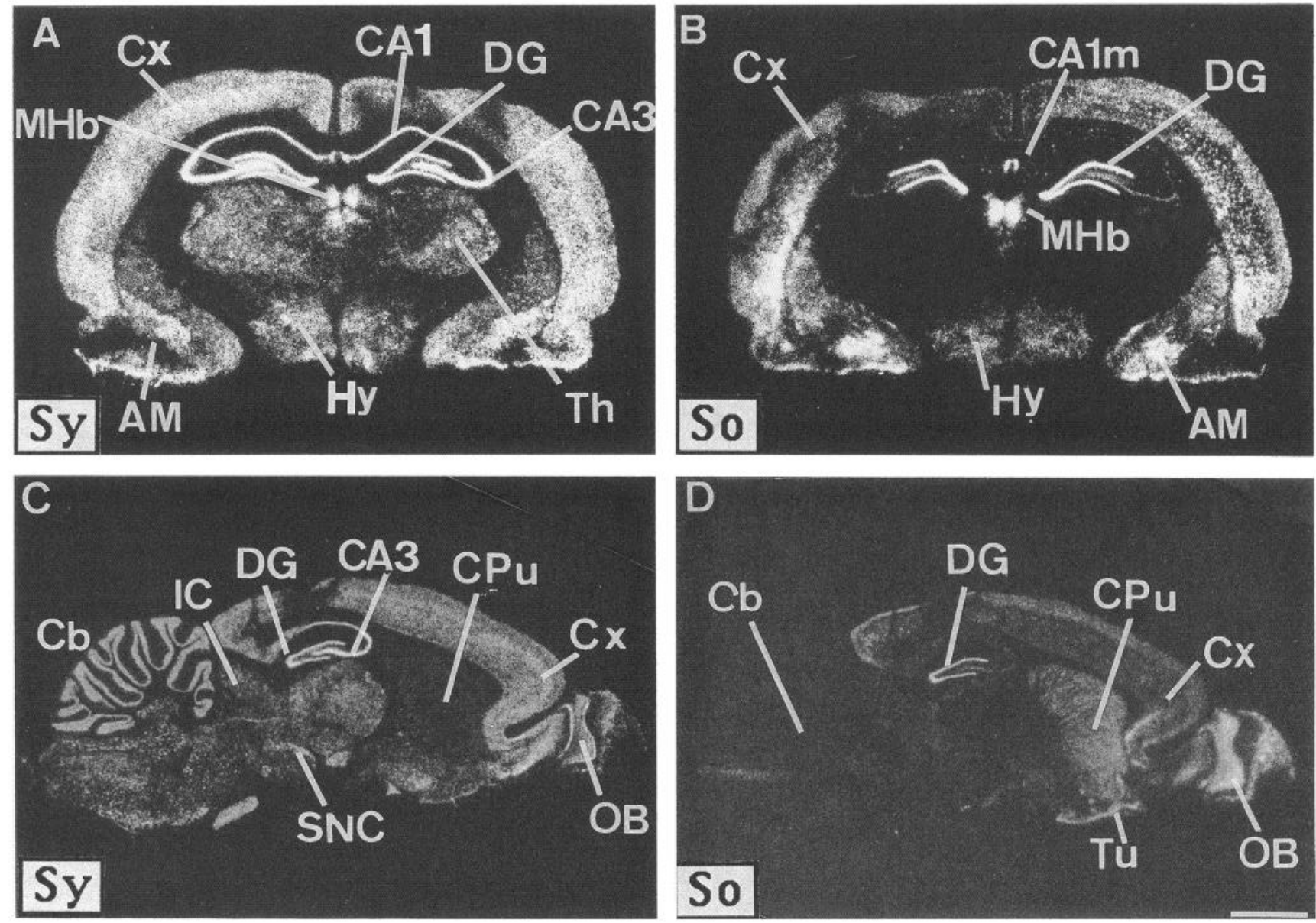

Figure 2. In situ hybridization of synaptophysin and synaptoporin mRNAs in coronal $(A$ and $B)$ and sagittal $(C$ and $D)$ sections of rat brain. Images of sections hybridized with synaptophysin $(A$ and $C ; S y)$ and synaptoporin $(B$ and $D ; S o)$ probes. $A M$, Amygdala; $C b$, cerebellum; $C P u$, caudate-putamen; $C x$, cortex; $D G$, dentate gyrus; $H y$, hypothalamus; $I C$, inferior colliculus; $M H b$, medial habenula; $O B$, olfactory bulb; $S N C$, substantia nigra compacta; $T h$, thalamus; $T u$, olfactory tubercle. Exposure was on Kodak X-Omat film for 1-8 weeks (no significant differences in relative labeling were revealed when varying exposure times within this interval). Scale bar, $3.5 \mathrm{~mm}$ (for all panels).

\section{In situ hybridization}

To determine whether the two known members of the synaptophysin family exhibit similar patterns of expression in brain and spinal cord, we compared tissue hybridizations obtained with probes specific for synaptophysin and synaptoporin mRNAs. Macroscopic transcript distributions are shown in Figures 2 and 3 . Each probe produced regionally distinct hybridization signals. In contrast to synaptophysin mRNA, which was consistently expressed throughout the neuraxis (Figs. $2 A, C$; $3 A, B, E, G)$, synaptoporin transcripts displayed a more restricted distribution within telencephalic structures (Figs. 2B, $D$; $3 C, D, F, H)$. The use of additional probes complementary to different regions of the synaptophysin (ASy2) and synaptoporin (ASo2) mRNAs gave identical patterns of hybridization (not shown). No signal could be detected with the sense probes SSy and SSo when used under identical conditions and at the same specific activity (data not shown). Also, essentially no labeling was observed on sections hybridized in the presence of a large excess of the unlabeled oligonucleotide (data not shown). Table 1 summarizes the regions of adult rat brain and spinal cord where synaptophysin and synaptoporin mRNA hybridizations were observed. These data were compiled by evaluating both exposed x-ray films (see Figs. 2, 3) and emulsion-coated slides (compare Figs. 4, 5).

\section{Telencephalon}

Olfactory bulb. High levels of synaptophysin and synaptoporin hybridization were observed in the olfactory bulb (Figs. 2, 3). Both transcripts were seen in the glomerular cell layer (Figs. $3 A, C ; 4 A, B)$. In the external plexiform layer, synaptophysin and synaptoporin mRNAs were found in different types of cells. Synaptophysin transcripts were concentrated in neurons confined to the periglomerular region that may correspond to the external tufted cells (Fig. $4 A$ ), while synaptoporin transcripts were localized homogeneously in the external plexiform layer (Fig. 4B). Strong labeling was obtained in mitral cells with the synaptophysin, but not the synaptoporin, antisense oligonucleotides. Synaptoporin transcripts, however, appeared more concentrated in the internal granule cell layer.

Cortex. Both mRNAs were present in the cortex but showed different laminated distributions. Synaptophysin transcripts were detected in all layers, but notably in higher amounts in layers III-V (Fig. 4C). Synaptoporin-positive cells appeared essentially in two layers, a more superficial one formed by cells in lamina II (Fig. $4 D$ ) and a deeper layer of hybridizing cells in lamina VI (Figs. 2B, 3D). Labeling was mainly concentrated in the piriform cortex (Figs. $2 D, 3 D$ ) and possibly the claustrum and the dorsal endopiriform nucleus. Strikingly, a deep area of what appears to be layer VI of area 2 of the parietal cortex contained elevated 

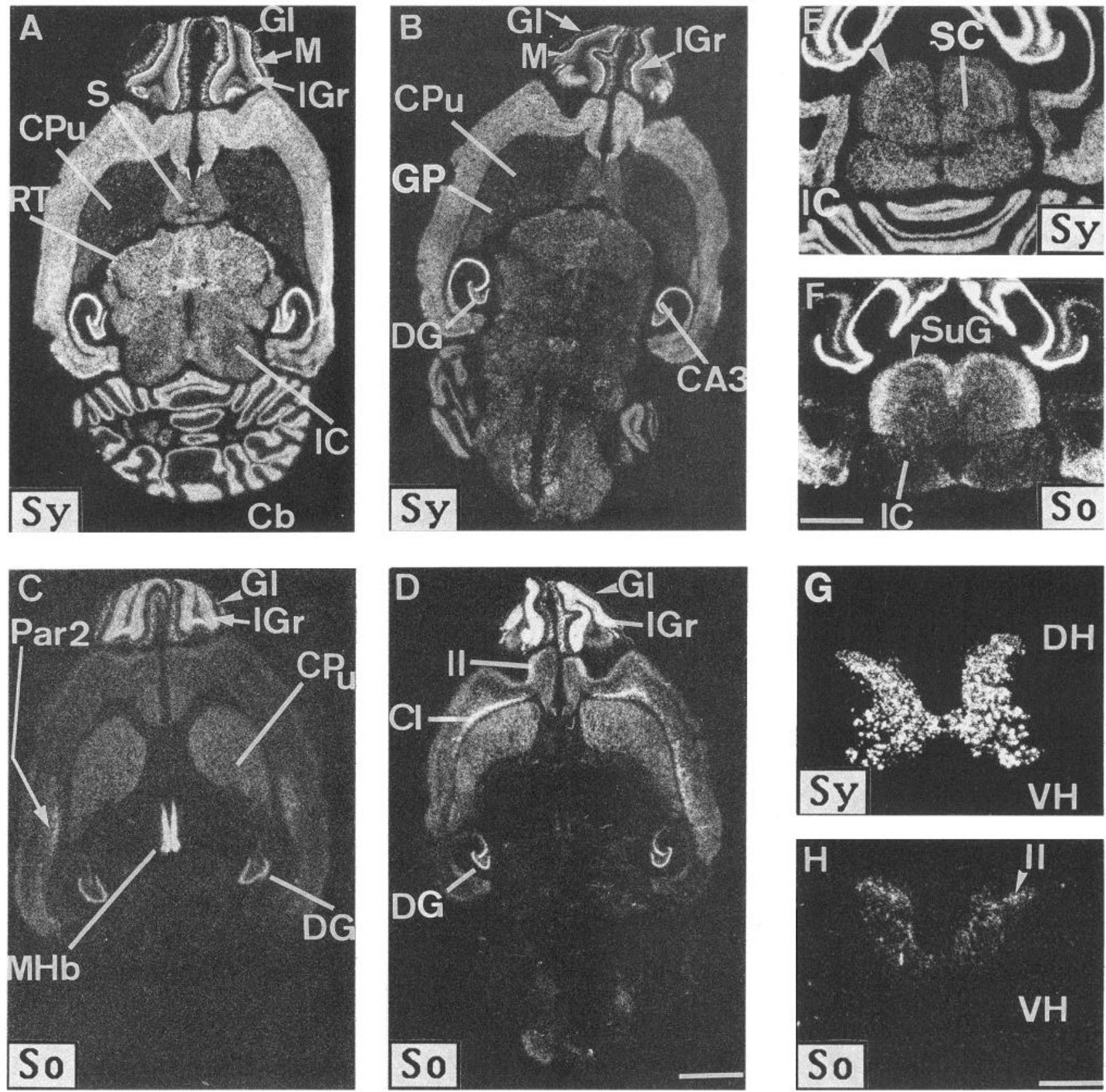

Figure 3. In situ hybridization of synaptophysin and synaptoporin mRNAs in horizontal sections of rat brain $(A-F)$ and coronal sections of spinal cord $(G$ and $H)$; synaptophysin $(A, B, E$, and $G ; S y)$ and synaptoporin $(C, D, F$, and $H ; S o)$ mRNA distributions. $C b$, Cerebellum; $C l$, claustrum; $C P u$, caudate-putamen; $D G$, dentate gyrus; $D H$, dorsal horn of the spinal cord; $G l$, glomerular layer; $G P$, globus pallidus; $I C$, inferior colliculus; $I G r$, internal granular cell layer; $M$, mitral cell layer; $M H b$, medial habenula; Par2, parietal cortex area $2 ; R T$, reticular thalamus; $S$, septum; $S C$, superior colliculus; $S u G$, superficial gray layer of the superior colliculus; $V H$, ventral horn of the spinal cord; $I I$, layer II of the spinal cord $(H)$ and layer II of the cerebral cortex $(D)$. Unlabeled arrowhead $(E)$ indicates clusters of silver grains in the area of the superficial gray and the optic nerve layers of the superior colliculus. Exposure was on Kodak X-Omat film $(A-D, 6 \mathrm{~d} ; E$ and $F, 8$ weeks; $G$ and $H, 4$ weeks). Scale bars: $A-D, 3.3$ mm; $E, F, 2.3 \mathrm{~mm} ; G, H, 1.1 \mathrm{~mm}$.

amounts of synaptoporin transcripts (Fig. $3 C, D$ ). This region is particularly rich in synaptoporin transcripts at the early stage of postnatal development (see Fig. 6).

Hippocampus. In hippocampus, there were again clear differences in the relative distributions of synaptophysin and synaptoporin transcripts (Figs. 2, 3, 5). Strong hybridization to synaptophysin mRNA was evident throughout the hippocampus (CA1-CA4 areas) and in the dentate gyrus. Localization of transcripts at the cellular level is shown in Figure 5. Synapto- physin-positive CA3 and CA4 pyramidal cells could be seen in addition to labeled granule cells in the dentate gyrus (Fig. $5 A, B$ ). Synaptoporin labeling was restricted to the granule cells of the dentate gyrus and cells of area CA4 and the most medial region of area CA1 (Figs. $2 B, 5 C, D$ ). CA 3 pyramidal cells were poorly labeled by the synaptoporin probe, although many scattered nonpyramidal cells (possibly interneurones) in the radiatum and oriens layers hybridized.

Amygdala. Synaptophysin-positive cell bodies were found in 

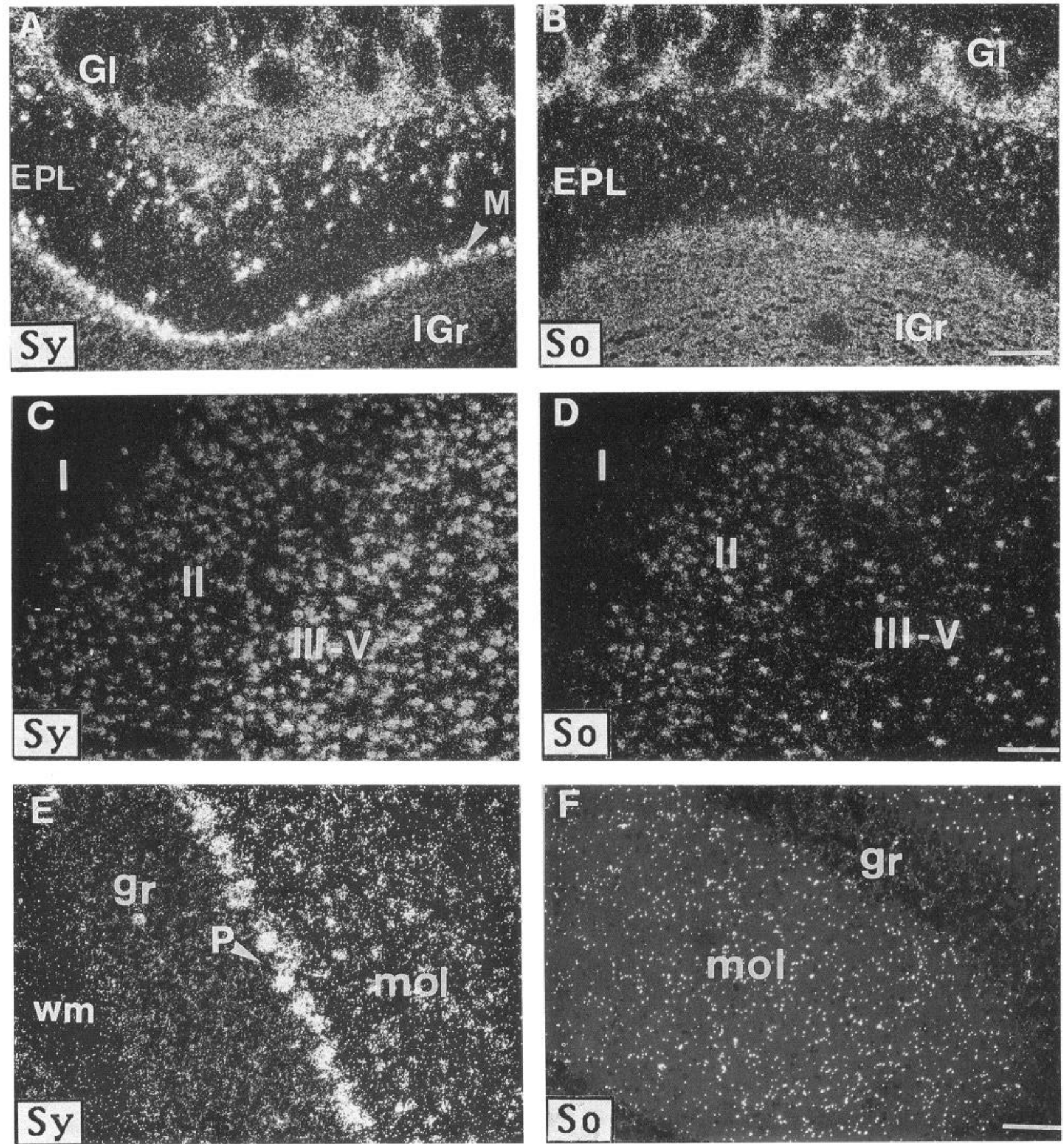

Figure 4. Low-power dark-field photomicrographs of olfactory bulb $(A$ and $B)$, cerebral cortex $(C$ and $D)$, and cerebellum $(E$ and $F)$ : synaptophysin $(A, C$, and $E ; S y)$ and synaptoporin $(B, D$, and $F ; S o)$ mRNA distributions. $E P L$, External plexiform layer; $G l$, glomerular layer; $g r$, granular cell layer; $I G r$, internal granular cell layer; $M$, mitral cell layer; $m o l$, molecular layer; $P$, Purkinje cell layer; $w m$, white matter; $I-V$, layers of the cerebral cortex. Exposure time of the emulsion-coated slides was 8 weeks. Scale bars: $A, B, 370 \mu \mathrm{m} ; C, D, 110 \mu \mathrm{m} ; E, F, 100 \mu \mathrm{m}$.

all nuclei of the amygdaloid complex (Fig. $2 A$ ). Synaptoporin mRNA was restricted to the medial amygdala nuclei (Fig. $2 B$ ).

Caudate nucleus. Caudate-putamen was one of the rare areas where synaptoporin transcripts were more abundant than synaptophysin mRNA (compare Fig. $3 B, D$ ). In contrast, synaptophysin-positive cells were observed in the globus pallidus where synaptoporin antisense oligonucleotide produced no detectable hybridization. Adjacent to the caudate-putamen, hybridization of synaptophysin (Fig. $2 C$ ) and, more intensely, synaptoporin (Fig. $2 D$ ) probes was observed in the olfactory tubercle.

\section{Diencephalon}

Thalamus-Hypothalamus. Differential distributions were also seen in these areas. Synaptophysin transcripts were ubiquitous in all thalamic and hypothalamic nuclei (Figs. $2 A, C ; 3 A$ ), and particularly high amounts were present in the reticular thalamus 

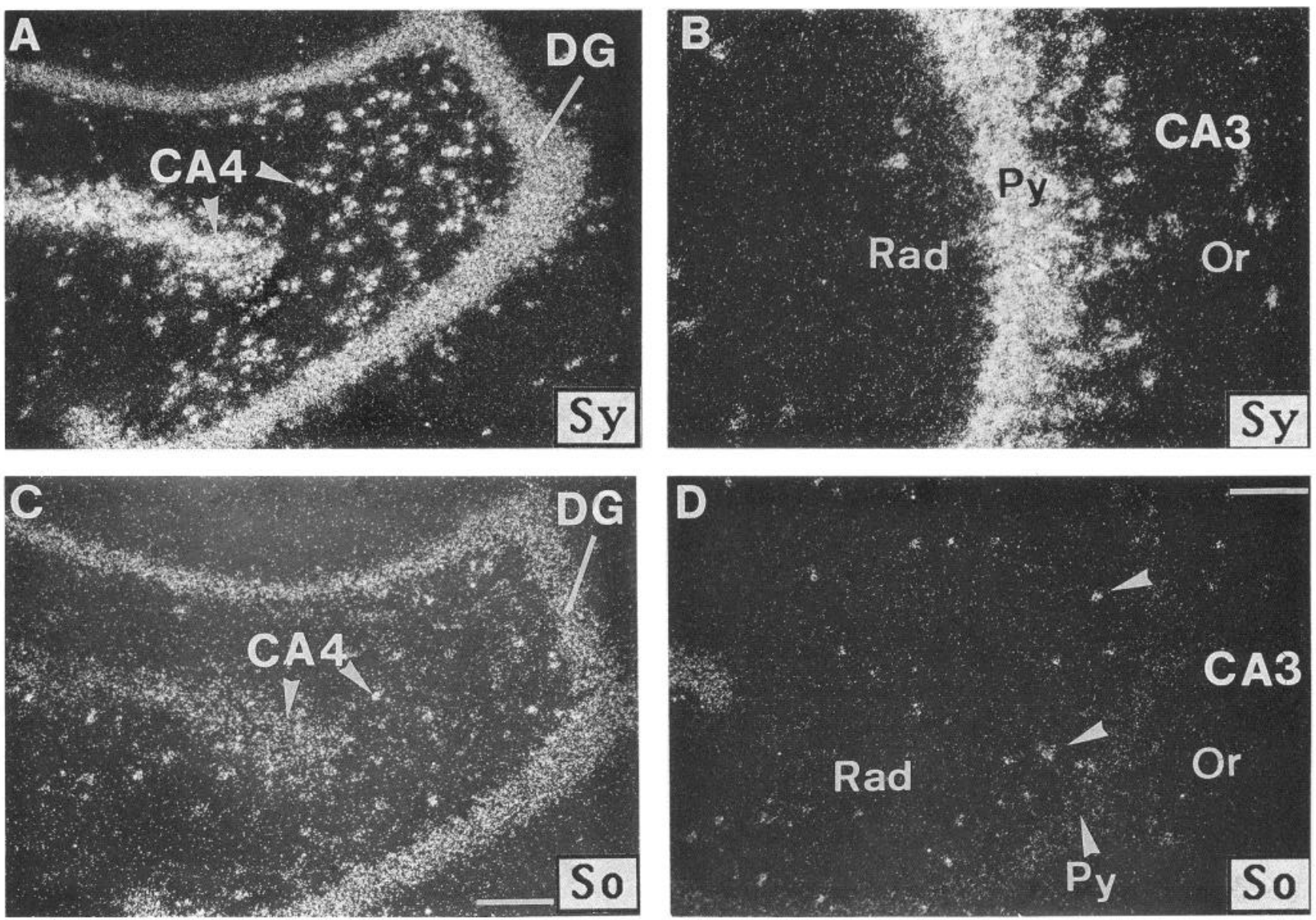

Figure 5. Low-power dark-field photomicrographs of hippocampus: synaptophysin $(A$ and $B ; S y)$ and synaptoporin $(C$ and $D$; So $)$ transcript distributions. Unlabeled arrowheads $(D)$ show scattered labeled cells of CA3 area. $D G$, Dentate gyrus; $O r$, oriens layer; $P y$, pyramidal layer; Rad, radiatum layer. Exposure time of the emulsion-coated slides was 8 weeks. Scale bars: $A, C, 70 \mu \mathrm{m} ; B, D, 40 \mu \mathrm{m}$.

(Fig. $3 A$ ). In contrast, no synaptoporin-positive cells could be detected in the thalamus (Figs. $2 B, D ; 3 C$ ), and only weak signals were observed (Fig. $2 B$ ) in the hypothalamus.

Habenula. Strong hybridization was seen with both probes in the medial habenula (Fig. $2 A, B$ ).

\section{Midbrain}

Colliculi. Distinct distributions of synaptophysin and synaptoporin transcripts were found in the superior and inferior nuclei (Fig. 3E,F). Synaptophysin mRNA was revealed throughout all areas of the superior and inferior colliculi. A slightly higher number of labeled cells was found in the superficial gray and the optic nerve layers of the superior colliculus (Fig. $3 E$ ). Synaptoporin transcripts were only detected in the superficial gray layer of the superior colliculus (Fig. $3 F$ ).

Substantia nigra compacta. Synaptophysin-positive cells were observed in this area (Fig. 2C), while synaptoporin transcripts were not detectable.

Cerebellum. The most striking difference in expression of synaptophysin and synaptoporin transcripts appeared in the cerebellum. A strong hybridization signal of the synaptophysin probe was seen in this area (Figs. 2C, 3A). Purkinje cells and, to a lesser extent, the stellate/basket interneurons of the molecular layer and the granular cells were intensely labeled (Fig. $4 E$ ). In contrast, the synaptoporin antisense oligonucleotide produced no detectable hybridization (Figs. $2 D, 3 C, 4 F$ ) in any cell type of the cerebellum, even after exposure times of up to 2 months.

\section{Spinal cord}

Synaptophysin transcripts seemed to be abundant in all neurons of the spinal cord (Fig. $3 G$ ). In contrast, synaptoporin mRNA was only revealed in layer II of the dorsal horn (Fig. $3 \mathrm{H}$ ); these hybridization signals were, however, much weaker than those obtained with the synaptophysin oligonucleotide. Thus, motor neurons apparently do not express synaptoporin mRNA. In contrast, dorsal root ganglia were labeled with both synaptophysin and synaptoporin antisense probes (data not shown).

Differential distribution of synaptophysin and synaptoporin transcripts during postnatal development

In situ hybridization experiments at different stages of postnatal development (Fig. 6) revealed significant changes in synaptophysin and in particular synaptoporin mRNA expression during the first 2 weeks after birth.

\section{Synaptophysin}

Figure 6, $A, C, E$, and $G$, was obtained in one experiment under identical conditions to allow comparison of the amount of transcripts at different stages of development. Synaptophysin mRNA was widely distributed in the brain already at postnatal day 0 
Sy
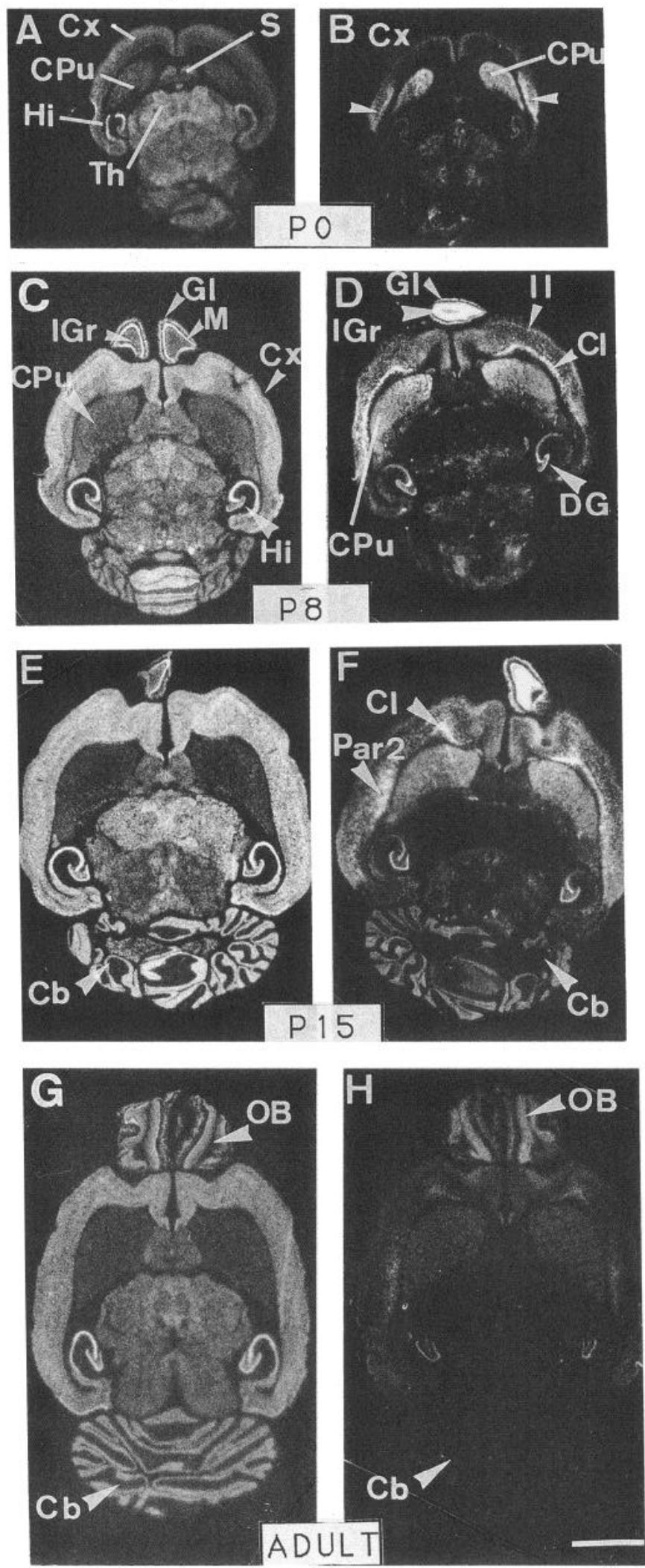

Figure 6. In situ hybridization of synaptophysin and synaptoporin mRNAs in horizontal sections of rat brain during development: synaptophysin $(A, C, E$, and $G ; S y)$ and synaptoporin $(B, D, F$, and $H ; S o)$ probes. Brain sections of P0 $(A$ and $B), \mathrm{P} 8(C$ and $D), \mathrm{P} 15(E$ and $F)$, and adult $(G$ and $H)$ are shown. Unlabeled arrowheads $(B)$ indicate Table 1. Relative abundance of mRNA in different regions of the rat
CNS

\begin{tabular}{|c|c|c|}
\hline Area & Synaptophysin & Synaptoporin \\
\hline \multicolumn{3}{|l|}{ Neocortex } \\
\hline Layers II-III & + & + \\
\hline Layers IV-V & +++ & + \\
\hline Amygdala & ++ & + \\
\hline \multicolumn{3}{|l|}{ Olfactory bulb } \\
\hline Periglomerula & ++ & ++ \\
\hline External plexiform layer & ++ & ++ \\
\hline Mitral cell layer & +++ & ND \\
\hline Internal granule cell layer & + & +++ \\
\hline \multicolumn{3}{|l|}{ Hippocampus } \\
\hline Dentate gyrus & +++ & ++ \\
\hline \multicolumn{3}{|l|}{ Pyramidal cell layer } \\
\hline CA1 & +++ & ++ \\
\hline CA3 & +++ & ND \\
\hline CA4 & +++ & ++ \\
\hline \multicolumn{3}{|l|}{ Striatum } \\
\hline Caudate-putamen & + & ++ \\
\hline Globus pallidus & + & ND \\
\hline Septum & ++ & ND \\
\hline Thalamus & +++ & ND \\
\hline Hypothalamus & ++ & + \\
\hline \multicolumn{3}{|l|}{ Epithalamus } \\
\hline Medial habenula & +++ & +++ \\
\hline Superior colliculus & ++ & ++ \\
\hline Inferior colliculus & ++ & + \\
\hline \multicolumn{3}{|l|}{ Cerebellum } \\
\hline Molecular cell layer & ++ & ND \\
\hline Purkinje cells & +++ & ND \\
\hline Granular cell layer & + & ND \\
\hline \multicolumn{3}{|l|}{ Spinal cord } \\
\hline Dorsal horn & +++ & ++ \\
\hline Ventral horn & +++ & ND \\
\hline
\end{tabular}

Relative expression levels were estimated by visual comparison of several autoradiographic films and emulsion-coated slides hybridized to probes of comparable specific activities. Hybridization signals above background were classified as follows: ND, not detectable; + , moderate; ++ , high; +++ , very high.

(P0). Thereafter, an increase of synaptophysin mRNA levels was observed that reached a maximum at P15. This increase was apparent in all areas of the brain, with the exception of the caudate-putamen, where some decrease was noted between P8 and P15. After P15, a general decrease of synaptophysin hybridization signals was observed in all brain regions examined.

clusters of silver grains in deep layers of possibly area 2 of parietal cortex. $C b$, Cerebellum; $C l$, claustrum; $C P u$, caudate-putamen; $C x$, cortex; $D G$, dentate gyrus; $G l$, glomerular layer; $H i$, hippocampus; $I G r$, internal granular cell layer; $M$, mitral cell layer; $O B$, olfactory bulb; Par2, parietal cortex area 2; $S$, septum; $T h$, thalamus; $I I$, layer II of the cerebral cortex. Exposure to X-Omat film was for $4 \mathrm{~d}(A, C, E$, and $G)$ and $13 \mathrm{~d}(B, D, F$, and $H)$. Scale bar, $4.5 \mathrm{~mm}$ (for all panels). 


\section{Synaptoporin}

At all stages of development analyzed here, synaptoporin-positive cells were less abundant than cells showing synaptophysin transcripts. Therefore, the autoradiographs displayed in Figure $6, B, D, H$, and $F$, were exposed three times longer than those showing the corresponding synaptophysin hybridization patterns. At P0 (Fig. 6B) and P8 (Fig. 6D), synaptoporin transcripts were mostly seen in the caudate-putamen, in the deeper layer of the parietal area of the cerebral cortex, and, to a lesscr cxtent, in the most superficial layer of the frontal cortex. At P15 (Fig. $6 F$ ), hybridization levels reached maximal levels and strongly decreased thereafter, a finding similar to that obtained with the synaptophysin probe (see above). Moreover, synaptoporin-positive cells were observed in the P15 cerebellum, a structure not detectably labeled in the adult rat (Fig. $6 H$ ) even after prolonged periods of exposure (Fig. 3, and data not shown).

\section{Discussion}

In this article, we report the first in situ hybridization study in rat brain of synaptophysin, a well-described synaptic vesicle protein, and a comparison of its regional expression with that of a recently identified synaptophysin homolog, synaptoporin (Knaus et al., 1990). The latter protein also is present in small synaptic vesicles; however, its distribution and functional properties have not been analyzed. Thus, the data presented horc constitute the first information about the localization of this new component of synaptic vesicles in the CNS.

\section{Localization of synaptophysin and synaptoporin transcripts in the adult rat brain}

Synaptophysin and synaptoporin probes produced distinct patterns of hybridization in different regions of the rat CNS. Synaptophysin mRNA was expressed in a great majority of neurons, which is consistent with previous immunocytochemical and immunoprecipitation data showing that synaptophysin is present in $\geq 90 \%$ of brain small synaptic vesicles, regardless of the type of neurotransmitters contained (Wiedenmann and Franke, 1985; Floor and Feist, 1987). In contrast, synaptoporin transcripts were enriched in very restricted areas, which mainly belong to forebrain structures. In some of these regions, hybridization signals were more prominent than with a synaptophysin probe. For example, synaptoporin transcripts were concentrated in the internal granular cell layer of the olfactory bulb, the claustrum, area 2 of the parietal cortex, and the caudate-putamen. Whether labeling intensities correlate with cell density, number of synaptic vesicles, or vesicle protein turnover remains unclear. Also, we cannot exclude low levels of synaptoporin mRNA in other brain regions that may have not been revealed by the oligonucleotide hybridization method used in this study; however, in the latter case they can be estimated to be at least 50-fold lower than synaptophysin mRNA contents, as judged from differences in hybridization intensities and/or exposure times. Thus, different interpretations of our data are possible. The two homologous vesicle proteins may be located in different neurons, and in the areas mentioned above, synaptophysin may not be expressed in every nerve cell. Alternatively, both proteins may be present within the same neuron, however, either in different subpopulations of synaptic vesicles or in the same organelle, but at variable stoichiometry. Although in view of our developmental studies this latter hypothesis appears less appealing, immunoprecipitation of isolated synaptic vesicles and immu- nocytochemistry of individual nerve terminals using specific antibodies against the two homologs are certainly required to discriminate these alternatives clearly.

\section{Comparison of synaptophysin and synaptoporin transcript patterns with known neurotransmitter systems}

Synaptophysin is believed to play an important role in neurotransmission at chemical synapses. A similar function has been proposed for synaptoporin (Knaus et al., 1990). Therefore, we compared the distribution of synaptoporin transcripts with the localization of well-characterized neurotransmitter systems. Although such comparisons are complicated by the fact that mRNAs are localized to cell bodies, whereas neurotransmitters and synaptic vesicle proteins are concentrated in axon terminals, the anatomy of synaptoporin transcripts appears not to correlate with that of any known transmitter substance (Emson, 1983). For example, no hybridization signals were seen in mitral cells of the olfactory bulb and in granular cells of the cerebellum that release glutamate, or in neurons of the globus pallidus and Purkinje cells containing GABA. Moreover, no synaptoporin-positive cells were detected in the ventral horn of spinal cord, which contains mainly cholinergic motor neurons. Also, the substantia nigra compacta rich in dopaminergic cells was devoid of synaptoporin mRNA. Finally, serotoninergic neurons in the raphe nucleus were also unlabeled with the synaptoporin probe.

Although synaptoporin hybridization patterns did not resemble the localization of any classical neurotransmitter, transcripts were often found in areas rich in peptidergic neurons, for example, caudate-putamen, the granular cell layer of the olfactory bulb, the dorsal horn of spinal cord, the olfactory tubercle, and dorsal root ganglia. Also, different regions known to contain cholecystokinin (Savasta et al., 1988), neuropeptide Y (Morris, 1989), or substance $P$ (Warden and Young, 1988) transcripts, for example, the claustrum, the medial habenula, and the superior colliculus, showed high levels of synaptoporin mRNA. In the dentate granule cells of hippocampus, the distribution of synaptoporin transcripts resembled the localization of dynorphin and enkephalin (Ben-Ari and Represa, 1990). Interestingly, synaptoporin mRNA seems to be present in a subset of neurons of the most medial part of the CA 1 area, which might correspond to cells described recently to contain neurotrophin-3 mRNA coding for a homolog of NGF (Phillips et al., 1990). For none of the aforementioned neuropeptides, however, do transcript distributions fully match that of synaptoporin mRNA. Moreover, release of neuropeptides is thought to occur from large dense-core vesicles, whereas synaptoporin, like synaptophysin, is localized in small synaptic vesicles (Knaus et al., 1990). Indeed, in olfactory bulb the distribution of transcripts of chromogranin A, a marker of large dense core vesicles (Lahr et al., 1990), does not resemble the localization of synaptoporin mRNA. Thus, synaptoporin may not be essential for release of a given neurotransmitter but, as suggested by preferential localization of its transcripts in telencephalic structures, associated with specific pathways implicated in higher functions of the brain.

Synaptophysin and synaptoporin in situ hybridization patterns do not correlate with the distribution of other synaptic vesicle proteins

Two homologs of another major vesicle membrane protein, VAMP or synaptobrevin, have been described in rat (Elferink et al., 1989), and heterogeneous distributions of the corresponding transcripts have been reported (Trimble et al., 1990). How- 
ever, no correlation was observed here with the localization of synaptoporin and synaptophysin mRNAs. Thus, several biochemically distinct subpopulations of small synaptic vesicles appear to exist in the CNS. Immunohistochemical studies have shown that synaptophysin and synapsin $\mathrm{Ib}$, one of the four homologs of the synaptic vesicle-associated protein family, show similar distributions in rat brain (Südhof et al., 1989). Furthermore, a recent report reveals synaptophysin to be more widespread than synapsins in retinal nerve terminals (Mandell et al., 1990), a region where heterogeneous distributions of synapsin I and II have been reported. Interestingly, in cerebellum, transcripts coding for synapsin IIa (Südhof et al., 1989) were not found in the Purkinje cells, which also lack synaptoporin mRNA. The differential distributions of these specific markers of synaptic vesicles probably reflect differences in the functional properties of central synapses.

\section{Appearance of synaptophysin and synaptoporin transcripts during postnatal development}

Synaptophysin and synaptoporin transcripts accumulated in distinct regions of the CNS and at different rates. A high level of synaptophysin mRNA was found already at P0 in most areas of rat brain. We even observed labeled cells in embryonic day 14 embryonic brain sections (B. Marquèze-Pouey, unpublished observations). Thus, synaptophysin gene expression seems to precede synaptogenesis, which constitutes a late event in brain development, occurring mainly between the first and third postnatal week in rat (Lohmann et al., 1978). However, very early synaptic contacts are known to be formed already in the embryo (Chun and Shatz, 1988). In this context, it is interesting to note that at $\mathrm{P} 0$ the superficial layer of the cortex was strongly labeled. This area is known to arise from transformation of the marginal zone where early synaptic contacts have been observed in cat brain (Chun and Shatz, 1988). Synaptic vesicles containing synapsin and $\mathrm{p} 65$, two proteins of small synaptic vesicles, have been visualized at that stage in nerve terminals by immunohistochemical techniques. After a maximal level of hybridization at P15, a general decrease of synaptophysin transcripts was observed in the adult brain. These data correlate with a continuous increase of synaptophysin protein contents during the first 3 weeks after birth (Knaus et al., 1986). A similar time course has also been reported for expression of synapsins $\mathrm{Ia}$ and $\mathrm{Ib}$ (Lohmann et al., 1978).

The developmental expression of synaptoporin mRNAs appears to be differently regulated, with a striking concentration of transcripts in the parietal area of the cortex and the striatum at P0. At P8 and P15, a gradient of hybridization signals was noted in the striatum, the rostral part of the caudate-putamen being the most strongly labeled area. Similar gradients have been reported for the distribution of neurotransmitters and neuropeptides in the striatum (Graybicl and Ragsdalc, 1983). Synaptoporin-positive cells were also observed in the P15 cerebellum, while no transcripts were detectable in the adult. In conclusion, the differential developmental appearance of synaptophysin and synaptoporin transcripts further supports the idea that these two synaptic vesicle proteins are not localized in the same cells but constitute markers of distinct neuronal pathways.

\section{References}

Almers W, Tse FW (1990) Transmitter release from synapses: does a preassembled fusion pore initiate exocytosis? Neuron 4:813-818.
Aviv H, Leder P (1972) Purification of biologically active globin messenger RNA by chromatography on oligothymidylic acid-cellulose. Proc Natl Acad Sci USA 69:1408-1412.

Ben-Ari Y, Represa A (1990) Brief seizure episodes induce long-term potentiation and mossy fibre sprouting in the hippocampus. Trends Neurosci 13:312-318.

Betz H (1990) Homology and analogy in transmembrane channel design: lessons from synaptic membrane proteins. Biochemistry 29: 3591-3599.

Buckley K, Kelly RB (1985) Identification of a transmembrane glycoprotein specific for secretory vesicles of neural and endocrine cells. J Cell Biol 100:1284-1294.

Buckley KM, Floor E, Kelly RB (1987) Cloning and sequence analysis of cDNA encoding p38, a major synaptic vesicle protein. J Cell Biol 105:2447-2456.

Cathala G, Savouret J-F, Mendez B, West BL, Karin M, Martial JA, Baxter JD (1983) A method for isolation of intact, translationally active ribonucleic acid. DNA 2:329-335.

Chun JJM, Shatz CJ (1988) Redistribution of synaptic vesicle antigens is correlated with the disappearance of a transient synaptic zone in the developing cerebral cortex. Neuron 1:297-310.

Elferink LA, Trimble WS, Scheller RH (1989) Two vesicle-associated membrane protein genes are differentially expressed in the rat central nervous system. J Cell Biol 19:11061-11064.

Emson PC (1983) Chemical neuroanatomy. New York: Raven.

Floor E, Feist BE (1989) Most synaptic vesicles isolated from rat brain carry three membrane proteins, SV2, synaptophysin, and p65. J Neurochem 52:1433-1437.

Graybiel AM, Ragsdale CW Jr (1983) Biochemical anatomy of the striatum. In: Chemical neuroanatomy (Emson PC, ed), pp 212-253. New York: Raven.

Jahn R, Schiebler W, Ouimet C, Greengard P (1985) A 38,000-dalton membrane protein (p38) present in synaptic vesicles. Proc Natl Acad Sci USA 82:4137-4141.

Johnston PA, Südhof TC (1990) The multisubunit structure of synaptophysin. J Biol Chem 265:8869-8873.

Johnston PA, Jahn R, Südhof TC (1989) Transmembrane topography and evolutionary conservation of synaptophysin. J Biol Chem 264: $1268-1273$.

Kelly RB (1988) The cell biology of the nerve terminal. Neuron 1: $431-438$

Knaus P, Betz H, Rehm H (1986) Expression of synaptophysin during postnatal development of the mouse brain. J Neurochem 47:13021304.

Knaus P, Marquèze-Pouey B, Scherer H, Betz H (1990) Synaptoporin, a novel putative channel protein of synaptic vesicles. Neuron 5:453462.

Kumar NM, Gilula NB (1986) Cloning and characterization of human and rat liver cDNAs coding for gap junction protein. J Cell Biol 103: $767-776$.

Lahr G, Heiss C, Mayerhofer A, Schilling K, Parmer RJ, O'Connor DT, Gratzl M (1990) Chromogranin A in the olfactory system of the rat. Neuroscience 39:605-611.

Leube RE, Kaiser P, Seiter A, Zimbelmann R, Franke WW, Rehm H, Knaus P, Prior P, Betz H, Reinke H, Beyreuther K, Wiedenmann B (1987) Synaptophysin: molecular organization and mRNA expression as determined from cloned cDNA. EMBO J 6:3261-3268.

Loewenstein WR (1987) The cell-to-cell channel of gap junctions. Cell 48:725-726.

Lohmann SM, Ueda T, Greengard P (1978) Ontogeny of synaptic phosphoproteins in brain. Proc Natl Acad Sci USA 75:4037-4041.

Mandell JW, Townes-Anderson E, Czernik AJ, Cameron R, Greengard P, De Camilli R (1990) Synapsins in the vertebrate retina: absence from ribbon synapses and heterogeneous distribution among conventional synapses. Ncuron 5:19-33.

Morris BJ (1989) Neuronal localisation of neuropeptide Y gene expression in rat brain. J Comp Neurol 290:358-368.

Paul DL (1986) Molecular cloning of cDNA of rat liver gap junction protein. J Cell Biol 103:123-134.

Pfenninger K, Akert K, Moor H, Sandri C (1972) The fine structure of freeze-fractured presynaptic membranes. J Neurocytol 1:129-149.

Phillips HS, Hains JM, Laramee GR, Rosenthal A, Winslow JW (1990) Widespread expression of BDNF but not NT3 by target areas of basal forebrain cholinergic neurons. Science 250:290-294.

Rahamimoff R, De Riemer SA, Sakmann B, Stadler H, Yakir N (1988) 
Ion channels in synaptic vesicles from Torpedo electric organ. Proc Natl Acad Sci USA 85:5310-5314.

Rahamimoff R, De Riemer S, Ginsburg S, Kaiserman I, Sakmann B, Shapira R, Stadler H, Yakir N (1989) Ionic channels in synaptic vesicles: are they involved in transmitter release? Q J Exp Physiol 74:1019-1031.

Rehm H, Wiedenmann B, Betz H (1986) Molecular characterization of synaptophysin, a major calcium-binding protein of the synaptic vesicle membrane. EMBO J 5:535-541.

Savasta M, Palacios JM, Mengod G (1988) Regional localization of the mRNA coding for the neuropeptide cholecystokinin in the rat brain studied by in situ hybridization. Neurosci Lett 93:132-138.

Südhof TC, Lottspeich F, Greengard P, Mehl E, Jahn R (1987) A synaptic vesicle protein with a novel cytoplasmic domain and four transmembrane regions. Science 238:1142-1144.

Südhof TC, Czernik AJ, Kao H-T, Takei K, Johnston PA, Horiuchi A Kanazir SD, Wagner MA, Perin MS, De Camilli P, Greengard P (1989) Synapsins: mosaics of shared and individual domains in a family of synaptic vesicle phosphoproteins. Science 245:1474-1480.
Thomas L, Betz H (1990) Synaptophysin binds to physophilin, a putative synaptic plasma membrane protein. J Cell Biol 5:2041-2052.

Thomas L, Hartung K, Langosch D, Rehm H, Bamberg E, Franke WW, Betz H (1988) Identification of synaptophysin as a hexameric channel protein of the synaptic vesicle membrane. Science 242:1050-1053.

Trimble WS, Gray TS, Elferink LA, Wilson MC, Scheller RH (1990) Distinct patterns of expression of two VAMP genes within the rat brain. J Neurosci 10:1380-1387.

Warden MK, Young WS III (1988) Distribution of cells containing mRNAs encoding substance $P$ and neurokinin $B$ in the rat central nervous system. J Comp Neurol 272:90-113.

Wicdenmann B, Franke WW (1985) Identification and localization of synaptophysin, an integral membrane glycoprotein of $M_{r} 38,000$ characteristic of presynaptic vesicles. Cell 41:1017-1028.

Wisden W, Morris BJ, Hunt SP (1991) In situ hybridization with synthetic DNA probes. In: Molecular neurobiology-a practical approach, Vol 2 (Chad J, Whead H, eds), pp 205-225. Oxford: IRL. 